\title{
La acción artística como producción narrativa: subjetividades, performance y experiencia en el Penal Modelo Ancón II
}

The Artistic Action as Narrative Production: Subjectivity, Performance and Experience in the Ancón II Model Penitentiary

Magíster en Antropología y licenciada en Artes Escénicas por la Pontificia Universidad Católica del Perú (PUCP), y alumna del doctorado en Antropología de esa universidad. Desarrolla proyectos artísticos e investigaciones de artes escénicas como espacios de acción y reflexión comunitaria. Desde hace cinco años dirige el Proyecto de Artes Escénicas en el Penal Modelo Ancón II (INPE-PUCP). 



\section{La acción artística como producción narrativa: subjetividades, performance y experiencia en el Penal Modelo Ancón II The Artistic Action as Narrative Production: Subjectivity, Performance and Experience in the Ancón II Model Penitentiary}

Lorena Pastor Rubio

Pontificia Universidad Católica del Perú

pastor.1@pucp.pe

Recibido: 12-06-2019/Aceptado: 18-09-2019

https://doi.org/10.1880o/conexion.201902.007

\section{PALABRAS CLAVE / KEYWORDS}

Narrativas, subjetividad, performance, cárceles, artes escénicas, comunicación / Narratives, subjectivity, performance, penitentiary, performing arts, communication sciences

\section{RESUMEN}

En este artículo, busco reflexionar sobre la experiencia del taller de artes escénicas realizado con un grupo de jóvenes varones y mujeres en el Penal Modelo Ancón II en la ciudad de Lima entre los años 2014 y 2018. Me interesa revisar cómo las narrativas surgen de la subjetividad y, a su vez, la configuran, así como reflexionar sobre de qué manera los procesos y contextos donde se generan estas narrativas constituyen importantes unidades de análisis para entender los marcos que las producen. Planteo que su performance, entendida como acción corporal, en su mostrar hacer es capaz de generar espacios reflexivos de encuentro y comunica- ción con poder constitutivo y transformador, pero también de problematizar estos discursos, las acciones y los vínculos que configuran.

\section{ABSTRACT}

This article seeks to reflect on the experience of a performing arts workshop conducted with a group of young men and women in the Ancón II Model Penitentiary in the city of Lima between 2014 and 2018. The study attempts to review how the narratives arise from the subjectivity and, at the same time, configure it, as well as ponder on how the processes and contexts where these narratives are generated constitute important units of analysis to understand the frameworks that produce them. It is proposed that the performance of these young men and women, understood as a corporal action, in its showing doing is capable of generating reflective spaces of encounter and communication with constitutive and transformative power, but also can problematize these 
discourses, the actions and the links that they constitute.

\section{La acción artística como producción narrativa: subjetividades, performance y experiencia en el Penal Modelo Ancón II}

En un sentido importante, existo para $y$ en virtud de ti. [...] si no tengo un «tú» a quien dirigirme, me he perdido a «mí misma» (Butler, 2009, p. 50).

Desde el año 2014, coordino y dirijo un proyecto escénico que es producido por la Facultad de Artes Escénicas de la Pontificia Universidad Católica del Perú en convenio con el Instituto Nacional Penitenciario (INPE). El objetivo del proyecto artístico es generar, a través de talleres de creación escénica y la puesta en escena de obras, procesos reflexivos y experiencias comunitarias que hagan posible el encuentro entre los jóvenes internos participantes (jóvenes varones y mujeres), tanto con ellos mismos como con una colectividad mayor (otros internos del penal, familiares, comunidad, etcétera). A lo largo de estos casi seis años, hemos realizado seis talleres y cinco obras de teatro, así como diferentes espacios de discusión y reflexión respecto a la experiencia artística vivida en el penal. Una particularidad de nuestro proyecto es que ha logrado reunir tanto a población masculina como femenina dentro de la misma experiencia; ya son cerca de 80 los y las
Este artículo forma parte de la investigación de mi tesis doctoral, que tiene como tema la creación y producción de narrativas performativas por parte de este grupo de jóvenes (varones y mujeres) internos en el Penal Modelo Ancón II de la ciudad de Lima. En ella, busco reflexionar acerca de cómo estas narrativas constituyen importantes unidades de análisis y de qué manera su performance es capaz de generar espacios reflexivos de encuentro y comunicación con poder constitutivo y transformador; asimismo, me interesa observar cómo, a través de ellas, es posible poner en evidencia un sistema social, cultural y político, y agendas y paradigmas que sostienen y legitiman relaciones de poder.

\section{Consideraciones teóricas y metodológicas}

Antes de empezar, quisiera tomar en cuenta tres aspectos fundamentales que enmarcan la investigación y el artículo que presento.

El primero tiene que ver con el contexto en el que se inserta la investigación y la necesidad de poner en circulación estas narrativas, en tanto que son producidas por los internos y las internas participantes. Casi el $32 \%$ de la población penitenciaria en el Perú es joven (entre 18 y 29 años; Instituto Nacional Penitenciario, 2019), y este es el rango de edad que comparten los integrantes del grupo que conforma esta investigación. Muchos de los jóvenes 
ingresan al penal a los 18 años, la mayoría por el delito de robo agravado, que presenta el más alto porcentaje de internos e internas a nivel nacional (25.5\%); además, tienen penas privativas de libertad altas (de seis a ocho años; Instituto Nacional Penitenciario, 2019). Estos indicadores dan cuenta de lo que algunos autores entienden como una política de criminalización de la miseria (Wacquant, 1999) o una guerra contra los pobres (Ortner, 2016), y que legitima, fortalece y es funcional al sistema neoliberal. Para Chloé Constant (2016), el sistema judicial en el Perú termina siendo lo que denomina una «dictadura sobre los pobres» ${ }^{1}$ (p. 252), es decir, un mecanismo de control social de un Estado populista incapaz de atender las necesidades de una extensa población que se encuentra en estado de pobreza y pobreza extrema. Sostiene su argumento en aspectos legislativos tales como la denominada «tolerancia cero» frente a la delincuencia, que se plasma en una legislación con medidas de privación de libertad extensas, sin posibilidad de beneficios penitenciarios para los delitos más comunes: robo agravado, asalto, etcétera. Se trata, además, de delitos realizados en su mayoría por jóvenes provenientes de sectores pobres (Constant, 2016). Esta lógica de criminalización de la pobreza que sostienen estos autores (Ortner, 2016; Wacquant, 2009; Constant, 2016) explica, en gran medida, entre otros, aspectos del sistema jurídico, del sistema de seguridad y del tratamiento penitenciario vigente en el Perú hoy.

En ese sentido, propongo que es importante considerar el hecho de que estas narrativas son producidas por jóvenes que se encuentran privados de su libertad, al margen de la sociedad por haber cometido un delito contra la ley. Es decir, están sujetos al régimen penitenciario, que es fundamentalmente un régimen disciplinario. Es una disciplina entendida como una anatomía política (Foucault, 1979), esto es, una serie de estrategias y técnicas para controlar los cuerpos y dirigir las acciones de los internos especialmente hacia la disciplina y la productividad (Foucault, 1979; Matthews, 2003). Debemos tomar en cuenta también que el sistema penitenciario peruano presenta muchas limitaciones para poder alcanzar los objetivos trazados en términos de tratamiento y seguridad (Constant, 2016). El estar recluidos y recluidas los dota de un estigma (Goffman, 2012), es decir, una serie de atributos negativos que los coloca en una situación de deslegitimidad y desventaja frente al resto de la sociedad, paradójicamente en un sistema que tiene objetivos y metodologías que proponen rehabilitarlos para una futura reinserción social.

Un segundo aspecto por tomar en cuenta es la metodología empleada para el desarrollo de la investigación. El trabajo de campo, que tiene como eje la experiencia 
escénica, se focaliza en recoger la producción de narrativas, tanto textuales como corporales (lo que incluye el discurso verbal), de un grupo de jóvenes varones y mujeres internos e internas en el Penal Modelo Ancón II entre los años 2014 y 2019. Propongo entender la propuesta del diseño etnográfico de la investigación en dos dimensiones. Por un lado, la configuración del campo a partir y a través de un espacio de creación de narrativas performativas en el marco de un taller de artes escénicas y los espacios que se generan a través y a partir de él. La propuesta en esta línea se basa en la generación de un campo donde se explora, experimenta y elabora experiencia a partir y a través de la acción escénica, es decir, la performance. Esta acción está inserta en un contexto que involucra necesariamente la institución penitenciaria, sus autoridades y operadores; familiares de los y las participantes; y las audiencias. El objetivo metodológico es provocar y generar que los y las jóvenes participantes estructuren sus experiencias de vida desde la sensibilidad, sensorialidad y reflexividad a la que nos invita la acción artística y sus procesos. Las exploraciones que realizamos en los talleres tienen como punto de partida y materia prima para la creación la historia personal, que se comparte y se elabora colectivamente. Estos procesos artísticos hacen posible experimentar, por parte de los internos, ejercicios de revisión y reescritura de la historia personal para resignificarla desde el presente y darle un sentido. Esta metodología se en- marca en lo que se denomina practice as research (Kershaw, Miller, Whalley, Lee y Pollard, 2011), es decir, investigación desde la práctica artística, que tiene como característica esencial el hecho de que la principal ruta de búsqueda sea la acción y lo que emerge en el campo o en el espacio. Esto no es algo que se da de manera predeterminada, sino que se va elaborando y construyendo de manera práctica, intuitiva y, por ello mismo, reflexiva. La metodología, que se desprende de este principio, busca configurar un espacio de creación y constitución de experiencia en el que la agencia de los jóvenes juega un papel crucial.

Es a partir de este espacio de acción artística que nos vinculamos tanto con los participantes como con el recinto penitenciario y sus diversos agentes. En esta relación sitúo la segunda dimensión del diseño etnográfico: la observación del sistema penitenciario y su estructura a través de los discursos y las prácticas del personal de seguridad, de profesionales (psicólogos y asistentes sociales), y de la dirección del penal y autoridades del INPE. Recojo esta información a través de las técnicas de observación participante, conversaciones informales y entrevistas en profundidad. Al tener una relación directa con los operadores del sistema, tanto desde la línea de seguridad como desde la de tratamiento, pude observar cómo esta estructura y estas normativas se enuncian, se organizan, se aplican y operan. Esta dimensión del trabajo de campo 
me permitió tener información acerca de cómo los jóvenes internos accionan fuera del contexto del taller: en su vida cotidiana, en su relación con otros internos y otras internas, y con la autoridad.

Me interesa también traer a colación de manera crítica cuál es mi lugar en el campo como investigadora, en la medida en que genero el dispositivo y tomo decisiones. Un primer punto de partida es tomar conciencia del lugar desde el cual me coloco al realizar esta investigación. Por un lado, hay una agenda y una agencia compartida entre los jóvenes y todos los involucrados en poner el proyecto en movimiento: la intención de generar procesos reflexivos y materiales narrativos y discursivos que problematicen el fenómeno de la delincuencia y el estigma asociado a los jóvenes que se encuentran en un centro penitenciario. Desde aquí mi mirada, al no estar inmersa en la misma realidad, puede nutrir esta producción insertándola en un contexto social más amplio, así como discutirla, no solo desde los hallazgos del trabajo de campo, sino también a la luz de la producción académica pertinente. Una segunda dimensión es la afectiva y sensible, y es que se trata de procesos donde la subjetividad y la sensibilidad adquieren un lugar protagónico. De acuerdo con Abu-Lughod (2012):

El yo exterior no siempre permanece afuera. El antropólogo tiene una relación definitiva con el Otro de la investigación, no sólo como occi- dental, sino como francés en Argelia durante la guerra de independencia, o estadounidense en Marruecos durante la guerra árabe israelí de 1987. [...] «quien permanece» está en una posición específica en relación con la comunidad estudiada. [...] constantemente debemos atender la posicionalidad del yo antropológico y sus representaciones de los otros (pp. 135-136).

Este es un segundo punto de mi reflexión. En el caso de esta investigación y de la propuesta etnográfica, mi posición se ha ido construyendo, tejiendo y definiendo a lo largo del tiempo de permanencia en el penal y a raíz de las diversas experiencias vividas. Si bien tengo un poder como investigadora que lidera el equipo, este está sujeto a circunstancias, normas y una serie de factores propios de la institución penitenciaria. Esta tensión es parte importante de la información que recojo a lo largo del proceso.

Por otro lado, existe también un aspecto que se relaciona con la dimensión afectiva del investigador, en este caso, la mía. Mi vínculo con el proyecto de investigación y los y las jóvenes está cargado de afectos, respeto mutuo y colaboración, ya que todos participamos en el espacio que construimos. Si bien esto puede llevar a pensar que hay un obstáculo en términos de la distancia necesaria para la investigación, es cierto, también, que estas relaciones han permitido una producción 
discursiva rica y compleja. Ser consciente de este vínculo y de lo que a partir de ello detona forma parte del ejercicio reflexivo que propongo desarrollar. Antropólogos y antropólogas como Renato Rosaldo o Ruth Behar discuten y reflexionan acerca del lugar de la sensibilidad, la subjetividad y la vulnerabilidad del antropólogo y cómo incorporarlo de manera crítica en la investigación. Para Behar (1996), el antropólogo es un ser humano que llega al campo con ciertos conocimientos, prejuicios y agendas, y es constantemente afectado por lo que allí ocurre. Su presencia, además, genera y hace posible que los acontecimientos ocurran de la manera como él o ella los está observando, experimentando y registrando. En su propuesta, estar involucrado subjetiva y emocionalmente en la reflexión puede aportar significativamente a la manera como conocemos y producimos conocimiento: «[...] requiere una comprensión profunda de qué aspectos del yo son los filtros más importantes a través de los cuales uno percibe el mundo y, más particularmente, el tema que se estudia» (p. 13) ${ }^{2}$.

Asimismo, los fenómenos que el antropólogo narra ocurren de esa forma por su presencia, por su lugar en el campo, por lo que hace y por cómo lo interpreta: «[...] el observador [citando a George Devereux] "nunca observa el evento de comportamiento que 'habría tenido lugar' en su ausencia, ni escucha una explicación idéntica a la que el mismo narrador le daría a otra persona”» (Behar, 1996, p. 6). El reto para Behar es descubrir cómo introducir la historia personal en la narración etnográfica y el análisis de los hechos sociales que nos ocupan, sin convertirla en un documento netamente autobiográfico; cómo introducir en la reflexión las notas de campo que tienen que ver con momentos difíciles, por ejemplo, momentos de impotencia frente a determinadas situaciones. Behar manifiesta que escribir desde la vulnerabilidad «requiere habilidad y voluntad» (1996, p. 13). El objetivo es complejizar y profundizar nuestra reflexión y análisis, ser parte constitutiva de esa narrativa. En ese sentido, existe un interés en poner en circulación las percepciones y sensibilidades de los y las jóvenes participantes respecto a sus historias de vida y la manera como experimentan y dan sentido a su experiencia en la prisión. Estos repertorios están atravesados por el contexto, la agenda de los jóvenes y mi propia intención de explorar esas sensibilidades.

Esta investigación no solo se circunscribe al ámbito del taller de artes escénicas, sino que lo sitúa en el contexto del sistema penitenciario y desde ahí coloca las narrativas y sus procesos de producción -en lo cual me veo involucrada como investigadora- en un lugar crítico. Aquello que se dice y se silencia se contrapone o dialoga con lo que ocurre en otros espa- 
cios de acción y por otros agentes involucrados en el contexto. Es también a partir de esta tensión que busco desarrollar el análisis de estas narrativas y la acción performativa expuesta, para descubrir y recoger la complejidad de la producción, vinculando y problematizando todos los ámbitos que las atraviesan y en los que se enmarcan.

Finalmente, quisiera delimitar teóricamente algunos de los conceptos clave que se desarrollan en el análisis. Propongo entender las narrativas como construcciones o maneras de organizar la experiencia que, en este contexto, son elaboradas con la intencionalidad y conciencia de ser dichas y ser mostradas (carácter performativo). Es importante destacar que parten de la experiencia personal para actualizarla e intervenir en ella, para ponerse en circulación y en este ejercicio intervenir en la realidad de manera constitutiva. Bruner (1986) entiende la experiencia como la forma «como la realidad se presenta a la conciencia» (p. 6). Al ser la experiencia una vivencia personal, requiere ser expresada para poder ser comprendida. En ese sentido, la expresión es la manera «como una experiencia individual es enmarcada y articulada» (Bruner, 1986, p. 6). Para Bruner, la manera de interpretar culturalmente las experiencias de los otros -en términos hermenéuticos, citando a Dilthay- es a través de las expresiones, y pueden entenderse como «representaciones, performances, objetivaciones o textos» (1986, p. 5), que «constituyen uni- dades de significado» y «estructuran la experiencia» (1986, p. 6). En el contexto de esta investigación, esta construcción narrativa es una elaboración que está hecha para ser contada y puesta en escena; por lo tanto, implica un interlocutor. Está implícita una intencionalidad y desde ahí se configura un lugar de enunciación. Aquí propongo otra cualidad de las narrativas: el hecho de comprenderlas como resultados de procesos de producción y circulación en el marco de la performance; es decir, son actos que se caracterizan por su mostrar hacer (Schechner, 2002) y que cobran vida en el intercambio, la interacción y no únicamente como un ejercicio personal e individual. Por ello, es imposible desvincularlas de dos dimensiones: la subjetividad y la reflexividad. La subjetividad es la manera compleja en la que los sujetos percibimos y configuramos nuestra realidad y a nosotros mismos. La subjetividad incorpora la sensibilidad, la emoción, la corporalidad, la sensorialidad y el ejercicio cognitivo, para procesar la experiencia y proveerla de sentido. Pero no solo eso: implica una manera de acceder a uno mismo y constituirse de manera creativa como sujeto (Biehl, Good y Kleinman, 2007). La experiencia escénica ofrece una tecnología del yo (Foucault, 1990) para re-construirse, reflexionar sobre uno mismo y mostrar esos procesos. Si tomamos en cuenta que este ejercicio es realizado por jóvenes que se encuentran en el régimen penitenciario, encontramos una dinámica en la cual la noción de uno mismo, el self, se perfor- 
ma, se cuenta, se experimenta y toma acción de manera compleja y reflexiva. Brökling (2015) apunta al respecto:

Self como pliegue, esto quiere decir, formas más o menos estables de ponerse consigo mismo en relación. Un pliegue señala una relación del interior con el exterior, en la que ambos lados solo pueden ser pensados desde la relación de otro, respectivamente. El interior no es más que un exterior que se centra en sí mismo y viceversa (p. 39).

Según Schechner (2002) y Taylor (2007a, 2007b, 2016), las performances son repertorios o trozos de comportamiento que, tanto en su elaboración como en su puesta en acción y escena, señalan la propia acción humana, la subrayan. Se itera el comportamiento en diferentes contextos por distintos sujetos en función de determinadas agendas. Aquí radica la dimensión reflexiva a la que hago mención. Como afirma Schechner, «una performance toma lugar solo en la acción, interacción y relación» (2002, pp. 23-24), de ahí su carácter reflexivo y su capacidad de constituir el mundo, reconfigurándolo y resignificándolo. Las performances son acciones corporales y sensoriales que generan experiencia en el momento en que ocurren. $\mathrm{Si}$ nos situamos tanto en el marco de la cultura expresiva como en el de actos que, tal y como lo plantea Schechner, son enmarcados, elaborados y preparados para su mostrar hacer, entenderemos que implican un cuerpo que en el espacio está generando una experiencia no solo racional, sino sensible, que involucra la subjetividad. «Para Turner, [...] las performances revelaban el carácter más profundo, genuino e individual de una cultura» (Taylor, 2007a), pero, además, cómo esta se piensa a sí misma.

Sin embargo, si bien podemos atribuir a la performance esta capacidad, su poder constitutivo puede también operar en sentido contrario, es decir, reproduciendo y legitimando un orden social acorde con el sistema. Este punto nos lleva a considerar el uso estratégico que ciertos grupos de poder (intelectuales, económicos, políticos, entre otros) pueden otorgar a la performance y que también da cuenta de su poder constitutivo. La cultura se convierte en un recurso (Yúdice, 2002; Harvie, 2013), una manera de operar social y políticamente. Cuando hablamos del poder constitutivo de la performance, debemos tener claro que estas acciones no están desconectadas de un contexto: se desprenden de él de manera creativa; conllevan experiencia, agendas y la búsqueda por intervenir en el mundo.

Se trata entonces de narrativas que son el resultado de procesos subjetivos y reflexivos que muestran su acción de manera corporal, y cuya puesta en circulación busca generar experiencia que incida en la subjetividad y sea constitutiva del sujeto y de su entorno en términos relacionales. El grupo está compuesto por jóvenes que comparten una serie de características y 
condiciones. Una primera característica que quisiera recoger es el hecho de que todos y todas se encuentran privados de su libertad por haber cometido un delito contra la ley; en otros casos, los menos, por haber estado en el momento equivocado en el lugar equivocado. Todos, además, desde muy jóvenes (18, 19 años). Esta condición se enlaza directamente con una serie de circunstancias y experiencias de vida, también compartidas, pasadas y presentes: pobreza, violencia, marginalidad, necesidad de afecto y reconocimiento familiar. Asimismo, hay una necesidad de reivindicación, de restauración de vínculos familiares y sociales, pero, sobre todo, en una dimensión más personal, del reconocimiento de las capacidades y la propia valía. Estas experiencias y agendas personales se ven afectadas por aspectos más individuales, como el género, la historia personal, así como aquellos vinculados a las prácticas que realizan en el penal. En esa línea, y para este artículo, me interesa ocuparme de los lugares que encuentro comunes en función de los temas más recurrentes: la reflexividad y el perdón, la reconciliación personal y familiar, y la búsqueda de oportunidades.

\section{Experiencia en escena: narrativas y subjetividad}

Hay muchos espacios libres, por decirlo así, en la prisión. Como para que puedas hacer de todo: llorar, reír, recordar, anhelar, desear, arrepentirte y, mejor aún, cambiar. Cambiar de ser, de actitudes, de comportamientos. Olvidar todo lo malo que pasó por tu vida y volver a nacer, como quien dice. Solo pensando en que cada paso que des de hoy en adelante va a ser bueno, exitoso y, sobre todo, real. ¿Por qué no?

He hecho cosas difíciles. ¿Por qué no hacer algo nuevo y bueno? Mi nuevo reto: talleres de teatro dentro de prisión. Teatro, bueno, haré un par de Romeo y Julieta y Shakespeare in love, como para disfrutar del personaje y salir de los barrotes.

¡Qué! Esperen un segundo. Nada de Shakespeare in love ni Romeo y Julieta; que yo soy el propio personaje; que yo mismo hago mis escenas y mis secuencias. Eso está padrísimo, respondo a mi amiga, que, por cierto, es mexicana. [Mientras dice esto, voltea y saluda a R. Los participantes del taller han entrado al escenario, como si se tratase del patio de la alcaidía en el Penal Modelo Ancón II, donde se desarrolla el taller]. Wow, solo dije eso. Wooh, oh, yeah. Encontré la solución al final del total encierro. Qué alegría. Sentir ese respeto de tú a tú con otra persona que recién conoces. Bien, aprenderé cosas nuevas en el taller de teatro. Es un espacio fuera de esquemas, cero prejuicios.

Lindo mundo en el que me encuentro, por sobre todas las cosas que hay 
adentro en este encierro. [Voltea, ve a sus amigos y amigas jugando «zip, zap, boing», uno de los ejercicios que hacemos en el taller]. $\mathrm{Y}$ digo lindo porque vuelvo a ser un ser humano y no un reo más. [Se une al juego con sus compañeros].

\section{J., obra Yo y el mundo otra vez, 2017}

Esta narración da cuenta del sentido que tiene el espacio del taller de teatro para J., uno de los jóvenes participantes. Él cuenta cómo, a lo largo de su experiencia en el taller, se fue quebrando la idea de que el ejercicio artístico consistía en crear un personaje distinto a sí mismo y más bien se lo invitaba a visitar la propia historia personal para crear desde ahí. Este ejercicio lo implica de manera personal; lo involucra de manera protagónica no solo en el proceso creativo, sino en su resolución en el espacio escénico, donde convive con otros. J. trae al relato a su compañera mexicana, con quien no solo comparte, sino que también disfruta de esta experiencia sensible y subjetiva.

A partir de diversos dispositivos y detonantes creativos, los jóvenes son invitados a elaborar narrativas, a través del texto escrito o del cuerpo, que organizan y dan sentido a su experiencia de vida. El punto de partida es la biografía, la historia personal y cómo imaginan un futuro que aún no experimentan, pero sobre el cual quieren tener el poder y la capacidad de vivir, decidir y accionar como protagonistas. Estas narrativas tienen la cualidad de tener carácter performativo; es decir, se convierten en actos vitales (Taylor, 2007a, 2007b, 2016) de experiencia, que ocurren in situ frente a una audiencia y cobran vida a través del cuerpo y la voz de un ser humano particular. «Yo estoy en el teatro porque quiero que la gente sepa que existo»3, me comentó un día J. La cualidad performativa de las narrativas da potencia a la agencia personal porque es conducta restaurada (Schechner, 2002), susceptible de ser mostrada, ensayada, preparada y puesta en acción.

Me interesan en particular los procesos de elaboración y las narrativas producidas en este espacio porque parten de la subjetividad y son soportadas e impulsadas por una agencia individual que, en un espacio como un centro penitenciario, resulta urgente poner en acción y hacer visible para quienes las producen. Su naturaleza, además, tiene el componente performativo que las impregna de una cualidad: la conciencia de que serán dichas y puestas en acción para alguien, frente a alguien y desde uno mismo. Esto tiene una implicancia de mayor complejidad. Al ser corporales, no pueden escapar de un tramado de normas y limitaciones propias del sistema penitenciario y social que cobran vida no solo en la ciembre del 2017). 
conducta y el comportamiento - al codificar y decodificar lo que se dice, hace y experimenta-, sino también en la historia personal que se inscribe en el cuerpo y en la forma en que se resuelven, negocian y elaboran estrategias para la convivencia y sobrevivencia. Finalmente, se trata de narrativas que no solo dialogan, sino que también adquieren un sentido a partir de su convivencia con otras narrativas y corporalidades.

Mi interés en las narrativas se da también porque son el resultado de procesos de reflexión individual, de cómo los internos e internas buscan comprender su condición, organizar y encontrar estrategias para salir de esa realidad: evadirla, sobrellevarla, comprenderla o constituir otra. Durante el tiempo que llevo desarrollando el proyecto en el penal, he notado que en este contexto la abstracción resulta un ejercicio familiar. Por ello, elaborar a partir de la metáfora y de la subjetividad resulta efectivo, ya que es un lugar común. La escritura es también un ejercicio recurrente; a través de ella se logra traducir en palabras los sentimientos que cuesta verbalizar. En la vida cotidiana, ante la ausencia de un receptor «real», es decir, alguien que esté físicamente recibiendo esta información, el principal receptor termina siendo uno mismo. En el marco de la acción performativa propuesta, el texto escrito tiene un destinatario concreto e imaginado, que también se concretiza: los profesores, los compañeros del taller y el público de las obras. Aparece aquí esa presencia a la que hace referencia Butler (2009), ese destinatario que le da sentido y realidad al acto de comunicar. Dar cuenta de uno mismo 4 para entender la propia historia, organizarla y construir un nuevo lugar de enunciación para constituir una realidad sobre la cual se pretende o se lucha por tener libertad, agencia y poder.

Renato Rosaldo (1989) propone «comprender la conducta humana según se desarrolla a través del tiempo y en relación con su significado para los actores» (p. 58). Su propuesta busca otorgar un valor a la historia de vida a partir del recojo de las narrativas que, desde su perspectiva, han sido marginadas y no tomadas en cuenta como foco de comprensión y análisis. «Este nuevo giro ha transformado la tarea de la teoría, la que ahora debe atender asuntos conceptuales que vieron la luz gracias al estudio de casos particulares y no restringirse a la búsqueda de generalizaciones» (p. 58).

Rosaldo pone el foco en «un sujeto dentro de un determinado campo de relaciones sociales» (1989, pp. 23-24), a través de sus narrativas particulares de los relatos, porque encuentra en ellos la complejidad que se entraña detrás de las acciones y fenómenos sociales. 
Tengo algo muy importante que decirte ahora

Sentado frente al espejo, me sentía triste. Últimamente las cosas no me salían bien y, antes de empezar algo, ya sabía que no podía terminarlo. De pronto, sentía que el espejo me decía: tú puedes conseguir lo que quisieras, que primero tienes que tener confianza en ti mismo. Escucha estos consejos, me decía. Por qué no empiezas escribiendo las cosas que haces bien, como jugar fútbol. Y, si no sabes por dónde comenzar, puedes pedir ayuda y luego agregar algunas cosas que te gustaría hacerlo bien. Primero, acéptate como eres y anímate tú mismo. Recuerda con alegría, antes de irte a dormir, las cosas que te han hecho feliz durante todo el día. Intenta ser más específico. Si te centras en las cosas buenas que haces y en tus grandes cualidades, aprenderás a amarte y a aceptarte a ti mismo.

\section{J. L., obra Viajo por tus sueños, 2014}

Este texto fue creado bajo la siguiente premisa: «Tengo algo muy importante que decirte ahora». El destinatario es el mismo J. L. en un momento personal, y nos permite transitar por la percepción que tiene de sí mismo luego de mirar su rostro frente al espejo un día dentro del penal. De él emerge una voz que busca imponerse al abandono y a la pena que trae su condi- performa, se dirige también a sus compañeros y a una audiencia mayor. Se puso en escena de la siguiente forma: dos jóvenes, uno frente al otro, buscan encontrar actividades que bloqueen sus pensamientos negativos (leer, hacer manualidades, ejercicios dentro de la celda); al verse sumergido en la soledad y monotonía, aparece el impulso de lavarse el rostro y mirarse al espejo. Durante el proceso de análisis de la narración de J. L., propusimos que fueran dos los internos que pasaban por la situación en paralelo, mientras J. L. los observaba y leía al público el texto. Pregunté a R., uno de los jóvenes que estaba en la escena, de dónde creía que venía la reflexión que manifestaba J. L en su texto y él espontáneamente expresó:

Mirarme qué... Mirarme qué me está pasando, ¿no? Por qué no puedo seguir, no puedo seguir como era antes, ¿no? Y me miro al espejo y me doy cuenta que no soy el que era antes, que algo está cambiando en mí y no lo puedo permitir. Y ahí el espejo me comienza a hablar y me dice que me levante, que siga para adelante, que no me deje derrotar por los tropiezos, por los obstáculos. Que todavía soy joven y puedo hacer muchas cosas más. Y me levanto.

R., taller 2014

$R$. incorpora en su repertorio personal la narración de J. L. La hace propia en el momento en que la corporaliza para enten- 
der también su propia historia y proceso personal. Esta dinámica o juego en el que alguien o un grupo se apropia o asume la experiencia de otro para narrar la propia o reconfigurarla es parte del proceso de construcción de las narrativas que proponemos. En este contexto, no nos ocupa el carácter de «verdad» de lo narrado: la verdad se fundamenta en la agenda, en el contexto donde cobra vida y en el sentido que adquiere en los espacios donde performa. Va surgiendo una tecnología, en términos de Foucault (1990), de conocimiento personal, una manera de actuar sobre uno mismo.

Una vez más aparece en el material el reencuentro entre madres e hijos. Como una estampa o fotografía en la que pareciera que no transcurriera el tiempo. Las escenas tienen el mismo formato: la familia se encuentra entera en casa, haciendo actividades cotidianas y de pronto alguien toca la puerta. Es E., M., incluso Ed. La imaginación los hace construir una fotografía detenida que termina de completarse con el ingreso a la sala, al cuarto del hijo, a la mesa de trabajo de tareas, etcétera. Un abrazo sella el momento y la promesa de no separarse nunca más.

Notas de campo, 2015

La narración que traigo en este fragmento y que retrata cómo se imagina el reencuentro familiar dista mucho de la realidad que enfrentan muchos y muchas jóvenes al salir en libertad. En muchos casos, las familias que dejaron fuera cambian de dinámica, muchas madres y padres deben viajar para reencontrarse con sus hijos, o tienen muchas dificultades para reinsertarse a la vida tanto familiar como social. Sin embargo, el valor o potencial reflexivo de esta performance no radica en su carácter de verdad, sino en la forma como se elabora, se narra y se consolida en el momento que cobra vida.

Para mí, como lector etnográfico más que literario, la novela de Faulkner no apunta a una verdad previa a la narración, ni a una realidad dentro de ella, sino más bien a través de la compleja y dolorosa historia interminable de vidas vividas en compañía de recuerdos, a una manera de pensar en la experiencia (Steedly, 1993, p. 24)

Como menciona Steedly, el interés está puesto en la forma en que se piensa la experiencia, en la manera como esta es construida. Lo ficcional, entonces, es una vía para que las narraciones puedan tener un orden, una estructura y un sentido; enrumban la manera de completar vacíos o experimentar un futuro que aún no ocurre. Completar los vacíos o reelaborarlos con experiencias que se vivieron o se creyó vivir parte siempre de la imaginación y tiene un anclaje en la memoria 
(Morrison, 1995), pero también en aquello que se proyecta ser o vivir.

Las narrativas que brotan de estas experiencias permiten no solo organizar y dar un sentido a la propia vida, sino también la oportunidad de generar una voz y un cuerpo que se re-coloca en el mundo. La experiencia de vida se actualiza una vez que se performa, una vez que se convierte no solo en algo dicho, sino también en algo vivido y comunicado. Y, en ese sentido, incide en la constitución de los sujetos y en la manera en que configuran el mundo y su lugar en él.

Scott (1991) entiende la experiencia como un proceso de construcción de la subjetividad. Y, al ser dicha, tiene el poder y la posibilidad de dar cuenta de cuáles son los mecanismos y procesos a través de los cuales operan aspectos de la sociedad tales como la inequidad o la desigualdad, todo ello desde una perspectiva particular. Desde esta óptica, le interesa poner el foco en grupos humanos menos privilegiados o con menos poder:

The evidence of experience then becomes evidence for the fact of difference, rather than a way of exploring how difference is established, how it operates, how and in what ways it constitutes subjects who see and act in the world (p. 777).

Making visible the experience of a di- repressive mechanisms, but not their inner workings or logics; we know that difference exists, but we don't understand it as relationally constituted. For that we need to attend to the historical processes that, through discourse, position subjects and produce their experiences. It is not individuals who have experience, but subjects who are constituted through experience (p. 779).

Scott propone tomar las narrativas de las experiencias personales como evidencias porque ponen de manifiesto cómo opera el orden social. Entiende la evidencia como producción de un conocimiento que, en relación con otros, nos permite dar luz sobre discursos o historias de vida que las narrativas hegemónicas $u$ oficiales han mantenido ocultos. En ese sentido, me interesa entender el fenómeno de la delincuencia juvenil y de su experiencia desde un centro penitenciario a través de cómo los mismos protagonistas estructuran esta experiencia en la liminalidad a la que los conduce el encierro. Para Scott, sin embargo, el ejercicio de recoger la experiencia no debe estar desconectado de un contexto mayor donde nace y se inserta; a este ejercicio lo llama «historizar la experiencia»: «it is a historicizing that implies critical scrutiny of all explanatory categories usually taken for granted, including the category of "experience"» (1991, p. 780).

Scott nos invita a tener una mirada crítica de las experiencias narradas problematizando los diferentes elementos que 
entran en juego en el ejercicio reflexivo y analítico. Ello implica considerar tanto las categorías que utilizamos como el lugar desde donde observamos y producimos conocimiento, nuestra agenda y la de los sujetos, y los marcos donde se inscriben.

Es importante ser consciente de la conexión que existe entre el contexto y la agencia: qué está en juego en cada performance y cómo todo esto impacta la manera como se construye y enuncia la experiencia. Para Scott (1991), «seeing is the origin of knowing. Writing is reproduction, transmission-the communication of knowledge gained through (visual, visceral) experience» (p. 776). La escritura -entendida en esta investigación como escritura del texto escrito y del cuerpo en el espacio- está al servicio de lo que se quiere enunciar a partir de la experiencia. También afirma que esta escritura debe comprenderse inserta en un contexto y en un relato histórico. Aquí me gustaría traer a Judith Butler (2009) y su reflexión acerca de dar cuenta de uno mismo y vincularlo a la vez al pasaje etnográfico que acabo de presentar: «El "yo” no está al margen de la matriz prevaleciente de normas éticas y marcos morales en conflicto. En un sentido importante esa matriz es también la condición para la emergencia del “yo"» (pp. 18-19).

Judith Butler propone que la necesidad de dar cuenta de uno mismo emerge ante una situación de crisis en la que se ha roto el orden social. Dar cuenta de uno mismo está vinculado a justificar y recomponer la acción dentro de marcos éticos y normativos en los cuales los sujetos se encuentran inmersos: «Damos cuenta de nosotros mismos únicamente porque se nos interpela en cuanto seres a quienes un sistema de justicia y castigo ha puesto en la obligación de rendir cuentas» (Butler, 2009, p. 22).

Me interesa esta perspectiva para proponer uno de los cauces en los que circula la agenda e intencionalidad de estas narraciones. Para Butler, las narrativas que dan cuenta de uno mismo en estas circunstancias se enmarcan en las normas socialmente compartidas: ser un sujeto productivo, útil, dócil al sistema moral vigente es lo que la sociedad necesita escuchar. Asimismo, se necesita a un otro, un destinatario que decodifique estos discursos y acepte a quien está buscando esta restauración y recomposición del vínculo.

Esta perspectiva es útil, pero también puede agotarse como única categoría de análisis. La experiencia se enmarca en el contexto de un centro penitenciario y aquí estos marcos normativos son complejos y contradictorios. Si bien Butler no lo incorpora de manera categórica, sí existen intersticios donde los jóvenes pueden romper y jugar con estas normas, tanto a favor de ellas como en su contra. Hay un margen de acción y agencia individual y colectiva que negocia y juega con 
estos marcos. El objetivo es la pertenencia y sobrevivencia en un sistema sumamente complejo y contradictorio.

La norma no produce al sujeto como su efecto necesario, y el sujeto tampoco tiene plena libertad para ignorar la norma que instaura su reflexividad; uno lucha invariablemente con condiciones de su propia vida que podría no haber elegido. Si en esa lucha hay algún acto de agencia o, incluso, de libertad, se da en el contexto de un campo facilitador y limitante de coacciones. Esa agencia ética nunca está del todo determinada ni es radicalmente libre (Butler, 2009, p. 33).

Cuando el «yo» procura dar cuenta de sí mismo, puede comenzar consigo pero comprobará que ese «sí mismo» ya está implicado en una temporalidad social que excede sus propias capacidades narrativas; a decir verdad, cuando el «yo» procura dar cuenta de sí sin dejar de incluir las condiciones de su emergencia, tiene que convertirse, por fuerza, en teórico social.

La razón de ello es que el «yo» no tiene una historia propia que no sea también la historia de una relación -o un conjunto de relaciones - con una serie de normas (Butler, 2009, p. 19).

Durante el proceso de creación de la obra Desde adentro: historias de libertad 130 una escena que represente el último día de un interno en el penal. Dentro del grupo surgió un debate, ya que uno de los miembros quería presentar un momento en el que un técnico de seguridad pide dinero para dar trámite a la gestión de salida. Sin embargo, otro de los jóvenes que estaba en el grupo se negó a hacerlo, ya que «no quería problemas». Si bien es ilegal buscar un beneficio económico por parte de la autoridad en un proceso jurídicamente normado, el interno decide no contarlo para protegerse, en vista de que mostrar esta situación puede ganarle problemas a futuro. Vemos aquí que las narrativas no solo constituyen unidades de análisis respecto a lo que refieren o traen a la escena, sino, también, respecto a aquello que no se dice. Aquello que no se dice, en el ejemplo, refiere a los agentes de seguridad. Pero, también, puede referir a aspectos de la vida de los internos e internas que no aparecen en la producción discursiva y corporal, y que nos hacen problematizar esta producción con mayor complejidad.

En la obra Mi familia y yo (2016), se ponen en escena diferentes episodios de la vida familiar. En uno de ellos, se presenta el caso de R., quien es sentenciado por robar a un policía siendo inocente. En la obra se mostraba abiertamente cómo se acusa a un joven que iba transitando por la calle como culpable del robo a una pareja de transeúntes, delito que no cometió. En esa ocasión, era la primera vez que poníamos en escena la acción de robar y que se 
denunciaba públicamente una negligencia y error del sistema. Si bien la denuncia no afectaba directamente al sistema penitenciario, sí se ponía en cuestión la culpabilidad o inocencia de la audiencia presente en la función. La puesta en escena de la obra trajo como consecuencia reacciones por parte de la autoridad penitenciaria, encarnada en la directora:

A ver, buenas noches. Creo que la idea de que ustedes vinieran acá al patio principal -como me decía el jefe de seguridad, son más o menos 500 internos que están en estos momentos- no ha resultado. ¿Saben por qué? Porque la idea de sus compañeros de hacer un teatro [...] creo que se echó a perder. No es burlarse de las vivencias de sus compañeros, porque estoy segura que este teatro se basó en las historias que ustedes han vivido, ¿no? ¿Así fue?

Resulta pertinente la narrativa producida por la directora en ese contexto, en el que la obra constituía un evento que la institución penitenciaria aprueba, apoya y promueve a través de diferentes agentes y soportes institucionales. Sin embargo, quien asumía la autoridad del penal en ese momento ponía en cuestión la capacidad reflexiva de los internos y las internas participantes. La risa de la audiencia era asociada a la burla; reducía su respuesta a una reacción que limita su capacidad de análisis, su empatía y sensibilidad respecto a lo ocurrido. Se apropió de ese espacio para legitimar su poder y con ello su rol y lugar jerárquico, un ejercicio de poder que no solo afectaba al grupo de jóvenes, sino a todo el equipo de profesores y responsables del taller. Este evento y las narrativas que emergen en él nos permiten no solo poner en evidencia una mirada respecto al interno, sino también problematizar la institución penitenciaria, salir de categorías binarias y acoger la diversidad de enfoques, acciones y desafíos que enfrentan para echar a andar sus políticas y acciones de tratamiento y seguridad, que son parte del contexto en el que se mueve el proyecto y la investigación.

Las narrativas tienen poder: son capaces de organizar la experiencia para compartirla y darle un sentido. En el caso de los textos que he traído al artículo, hay una agenda muy presente por parte de los jóvenes en torno a concebir el lugar de enunciación como una pregunta -más que una afirmación - respecto a uno mismo: ¿quién soy y quién quiero ser? Una pregunta cuya respuesta busca afirmar una serie de valores y capacidades que se ponen en acción en la performance. Que, además, actualiza repertorios de la vida cotidiana en diálogo con otras narrativas y constituye nueva experiencia que se pone en circulación: mostrar las propias capacidades, el cambio individual, e invitar a brindar nuevas oportunidades.

${ }^{6}$ Comentarios de la directora del penal luego de la presentación de la obra Mi familia y yo, de diciembre del 2016. Su reclamo se dirigía hacia los internos que, como público, se habían reído en la escena del robo. 
En este escenario, la dimensión afectiva es un vínculo que define las relaciones dentro del espacio del taller y, a la vez, una manera de configurar la dinámica familiar que se encuentra dañada y postergada. La convivencia entre varones y mujeres posibilita este intercambio de experiencias y la ocasión de un juego de representación amplio en el que todos los roles aparecen en escena: padres, madres, hijos, hijas, hermanos, hermanas, entre otros.

La producción narrativa es capaz de generar nuevas narrativas que ponen en evidencia y en cuestión cómo cierto orden y poder busca instalarse y legitimarse. En ese sentido, es relevante considerar cuáles son las agendas que los jóvenes buscan constituir, así como los repertorios recurrentes en el marco de un sistema neoliberal que tiende no solo a criminalizar la pobreza, sino también a marginalizar a aquellos que no cumplen sus mandatos. ¿Cuál es el lugar y cómo son acogidas las expectativas y posibilidades de estos jóvenes? No solo intramuros, sino también afuera, una vez que recuperen su libertad. Parten de la subjetividad que es constitutiva de un sujeto en un espacio-tiempo determinado. Sin embargo, también existen limitaciones. Las narrativas no pueden dar cuenta del todo de lo vivido; como plantea Butler (2009), se enmarcan en estructuras normativas para ser codificadas y decodificadas, requieren a un otro que las reciba -quien también responde a marcos normativos-, $y$, si bien dan cuenta de cómo opera el orden social, no son suficientes para entenderlo. Para que puedan constituirse como evidencia (en términos de Scott, 1991), deben conectarse con procesos históricos o contextos sociales más grandes, problematizar categorías, ser conscientes de los procesos y contextos de donde emergen y a través de quién o quiénes se produce este conocimiento. En ese sentido, el último texto trae una narrativa que proviene del poder que representa el sistema, y cuestiona tanto la reflexividad de los jóvenes como el poder institucional que representamos, poniendo en cuestión el sentido de nuestro taller en el penal y todo lo que ello significa para los jóvenes, en términos de su subjetividad y, por lo tanto, de sí mismos. Es en este ejercicio crítico desde donde pretendo seguir desarrollando esta investigación, problematizar mi lugar, las agendas en juego y desde dónde miramos y enunciamos nuestros hallazgos. 


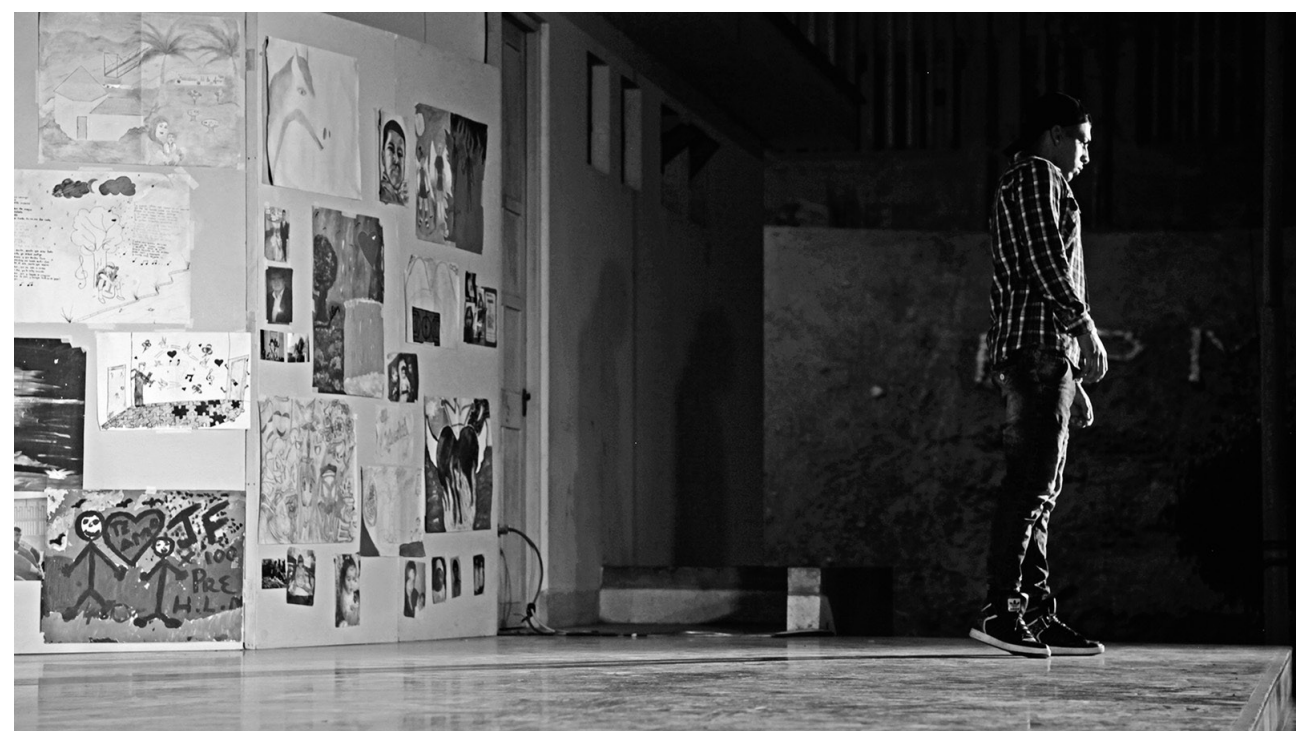

Imagen de la obra Mi familia y yo (2017) en el Penal Modelo Ancón Il de Lima, Perú. Foto: Nicolé H. 


\section{REFERENCIAS}

Abu-Lughod, L. (2012). Escribir contra la cultura (Trad. P. Castro). Andamios, 9(19), 129-157. Recuperado de http://www. scielo.org.mx/pdf/anda/v9n19/ v9n19a7.pdf

Behar, R. (1996). The vulnerable observer: Anthropology that breaks your heart. Boston, Estados Unidos de América: Beacon Press.

Biehl, J., Good, B. y Kleinman, A. (Eds.). (2007). Subjectivity: Ethnographic investigations. Berkeley, Estados Unidos de América: University of California Press.

Brökling, U. (2015). El self emprendedor. Sociología de una forma de subjetivación (Trad. K. Böhmer). Santiago de Chile, Chile: Universidad Alberto Hurtado.

Bruner, E. (1986). Experience and its expressions. En E. Bruner y V. Turner (Eds.), The Anthropology of experience (pp. 3-30). Chicago, Estados Unidos de América: University of Illinois Press.

Butler, J. (2009). Dar cuenta de sí mismo. Violencia ética y responsabilidad (Trad. H. Pons). Buenos Aires, Argentina: Amorrortu Editores.

Constant, C. (Ed.). (2016). Pensar las cárceles de América Latina. Lima, Perú: Instituto Francés de Estudios Andinos; Instituto de Estudios Peruanos; Pontificia Universidad Católica del Perú, Escuela de Gobierno y Políticas Públicas, Laboratorio de Criminología y Estudios sobre la Violencia.

Foucault, M. (1979). Vigilar y castigar. Nacimiento de la prisión. Madrid, España: Siglo Veintiuno.

Foucault, M. (1990). Tecnologías del yo y otros textos afines. Barcelona, España: Paidós.
Goffman, E. (2012). Estigma: la identidad deteriorada. Buenos Aires, Argentina: Amorrortu Editores.

Harvie, J. (2013). Fair play: Art, performance and neoliberalism. Londres, Reino Unido: Palgrave Macmillan.

Instituto Nacional Penitenciario. (julio, 2019). Informe estadístico. Lima, Perú: INPE. Recuperado de https://www. inpe.gob.pe/normatividad/documentos/3014-informe-estadistico-julio-2019/file.html

Kershaw, B., Miller, L., Whalley, J., Lee, R. y Pollard, N. (2011). Practice as research: Transdisciplinary innovation in action. En B. Kershaw y H. Nicholson (Eds.), Research methods in theatre and performance (pp. 63-85). Edimburgo, Reino Unido: Edinburgh University Press.

Matthews, R. (2003). Pagando tiempo. Una introducción a la sociología del encarcelamiento. Barcelona, España: Bellaterra.

Morrison, T. (1995). The site of memory. En W. Zinsser (Ed.), Inventing the truth: The art and craft of memoir (pp. 83-102). Boston, Estados Unidos de América: Houghton Mifflin.

Ortner, S. (2016). Dark anthropology and its others: Theory since the eighties. HAU: Journal of Ethnographic Theory, 6(1), 47-73. https://doi. org/10.14318/hau6.1.004

Rosaldo, R. (1989). Culture and truth: The remaking of social analysis. Boston, Estados Unidos de América: Beacon Press.

Schechner, R. (2002). Performance studies: An introduction. Nueva York, Estados Unidos de América: Routledge. 
Scott, J. (1991). The evidence of experience. Critical Inquiry, $17(4)$, 773-797. https://doi.org/10.1086/448612

Steedly, M. (1993). Hanging without a rope: Narrative experience in colonial and postcolonial Karoland. Princeton, Estados Unidos de América: Princeton University Press.

Taylor, D. (2007a). El espectáculo de la memoria: trauma, performance y política. Recuperado de http://performancelogia.blogspot.com/2007/o8/el-espectculo-de-la-memoria-trauma. html

Taylor, D. (2007b). Hacia una definición de Performance (Trad. M. Fuentes). Recuperado de http://performancelogia.blogspot.com/2007/o8/hacia-una-definicin-de-performance. html

Taylor, D. (2016). Performance. Duham, Estados Unidos de América: Duke University.

Wacquant, L. (1999). Las cárceles de la miseria. Buenos Aires, Argentina: Ediciones Manantial.

Wacquant, L (2001). The penalisation of poverty and the rise of neo-liberalism. European Journal on Criminal Policy and Research, 9(4), 401-412.

Yúdice, G. (2002). El recurso de la cultura. Usos de la cultura en la era global. Barcelona, España: Gedisa. 